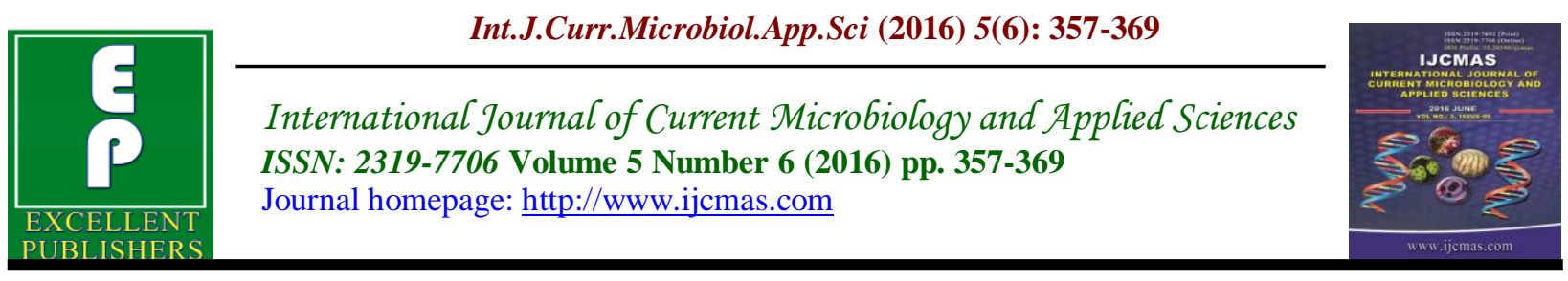

Original Research Article

http://dx.doi.org/10.20546/ijcmas.2016.506.041

\title{
Development of a Fermentation Medium for Production of Probiotics and their Use in Feed for Laying Hens
}

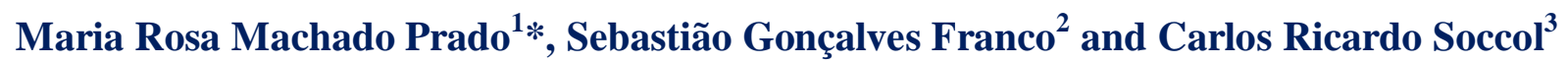 \\ ${ }^{1}$ Faculdades Pequeno Príncipe, Curitiba, PR, Brazil \\ ${ }^{2}$ DepartmentofVeterinary Medicine, Universidade Federal do Paraná, Curitiba, PR, Brazil. \\ ${ }^{3}$ DepartmentofBioprocessandBiotechnologyEngineering, Universidade Federal do Paraná, \\ Curitiba, PR, Brazil \\ *Corresponding author
}

\begin{abstract}
A B S T R A C T
Keywords

Probiotics,

Lactobacillus

fermentum,

laying hens,

eggs

production.

Article Info

Accepted:

15 May 2016

Available Online:

10 June 2016

The commercial egg production has passed through great advances in terms of much more productive ancestries and more healthful feed. All this progress necessary leads of the study of new techniques of production and improvements in the quality feed, aiming the nutritional requirements, one of the alternatives is the use of probiotics in the feed. The objective of this research was to evaluate the performance of commercial laying hens under the action of lactobacillus probiotics. Also, this research studied the optimization of the physical and nutritional conditions to obtain maximum biomass yield of Lactobacillus fermentum, using sugar cane molasses as a low cost culture medium. Several nutritional and physical conditions were tested, and finally, a kinetic study of the biomass production was made in order to confirm the results obtained from the optimizations processes. Results showed that the maximum biomass yield was $5,1 \mathrm{~g} / \mathrm{L}$ of culture medium with $7 \%$ of sugar cane molasses and $2,7 \%$ of yeast extract, under ideal fermentation conditions: temperature $37^{\circ} \mathrm{C}, \mathrm{pH} \mathrm{7,0}$ and 40 hours fermentation. Concerning to the egg production, there was a significant increase in a few months egg production por parte das laying hens that had received the feed with probiotics (Lactobacillus fermentum biomass) and had showed greater resistance to illnessesthat affect the digestive system.
\end{abstract}

\section{Introduction}

The industrial aviculture has being obtaining high growing taxes, mainly in the management of laying hens to eggs production. This growth is result of investments in the research directed to essential factors as diseases control to the maintenance of a good animal health, an adequate and consistent supply of good quality chicken feed and the genetic improvement of the races of laying hens that reflects in the increase of eggs production and also improves the eggs quality (Patterson and Burkholder, 2003; ScholzAhrens et al., 2008). Aiming to elevate the 
eggs production it is common the usage of growth promoters inlaying hensto improve the productive performance (Choe et al., 2012; Gaggia et al., 2010). Among the most used promoters are the antibiotics, enzymes, probiotics, prebiotics and symbiotics. The use of probiotics proposes benefits to the host health, they do not leave residuesin the animal origin products and do not favor resistance to drugs due to be a natural procedure (Giampauli et al., 2005; Mohitiasli et al., 2007).

The most modern definition to probiotics is the one preconized by WHO/FAO/OIE, 2003 that defines as an alive microbial alimentary supply, able to affect beneficially the host, improving the balance of its intestinal microbiota. In the aviculture the term probiotic designates the alimentary supply composed of pure culture or the mix of alive microorganisms, being the most used the acid lactic bacteria as Lactobacillus bulgaricus, Lactobacillus acidophilus, Lactobacillus casei, Enterococcus faecium, Enterococcus faecalis, Bifidobacterium sp, Bacillus sp, and also yeasts can be applied (Cantarelli et al., 2005). The main feature of these microorganisms is the capacity to install itself and proliferates in the gastrointestinal tract favoring the balance of the intestinal microbiota (Silva, 2000; Cantarelli et al., 2005; Bittencourt et al., 2006).

The application of probiotics implicates in the maintenance of an intestinal microbiota stable not pathogenic, its restoration after the unbalance and keep the health conditions of the hens (Kurtoglu et al., 2004). And for this it is necessary that the probiotics are innocuous, able to tolerate the low $\mathrm{pH}$ of the gastric juice, to resist to the bile action and the pancreatic and intestinal secretion, do not transport genes transmitter of resistance and to keep themselves viable for a long time during the storage (Awad et al., 2009; Choe et al., 2012).

The present study has as objective to optimize the cepa biomass Lactobacillus fermentum and to evaluate the probiotic potential of this cepa in laying hens.

\section{Materials and Methods}

\section{Microorganisms Cultures}

It was used cepa of Lactobacillus fermentum LPB isolated of the digestive tract of rustic chicken. The cepa of Lactobacillus fermentum was kept frozen in liquid nitrogen to $-196^{\circ} \mathrm{C}$, to this freezing first was realized a cultivation of Lactobacillus fermentum cepa in broth MRS (Man, Rogosa e Sharp) to $37^{\circ} \mathrm{C}$ by $48 \mathrm{~h}$, after the cultivation the means was centrifuged to $5000 \mathrm{~g}$ by 10 minutes with temperature of $4^{\circ} \mathrm{C}$, the supernatant was taken off and added to the sediment $1.5 \mathrm{~mL}$ of glycerol $10 \%$ and $0.5 \mathrm{~mL}$ of the reserved supernatant and soon after $1 \mathrm{~mL}$ aliquots were distributed in cryotubes and frozen.

The number of viable cells of inoculum was determined as colony-forming units (CFU). Decimal successive dilutions in $0.85 \% \mathrm{w} / \mathrm{v}$ $\mathrm{NaCl}$ solution, pour plate technique using $1.0 \mathrm{~mL}$ of sample in Lactobacillus MRS agar viable cells counting under. Then the plates and were incubated at $37^{\circ} \mathrm{C}$ for $48 \mathrm{~h}$. It was established the use of Lactobacillus fermentum cepa in the concentration of 10 ${ }^{10} \mathrm{CFU} / \mathrm{mL}$ this procedure was used in the further studies.

\section{Quantitative Analyzes}

Total sugars were analyzed by sulfuric acidphenol method (Dubois et al., 1956), reducing sugars by the DNS method (Miller, 1959), and protein quantified by Lowry's 
method (Lowry et al., 1951). All reagents were analytical degree unless otherwise specified.

To determinate the biomass it was realized by the method of dry weight, the sample was washed twice with deionized water with centrifugation cycles of $10.000 \mathrm{~g}$ by 15 minutes to the temperature of $4^{\circ} \mathrm{C}$ and posterior drying to $105^{\circ} \mathrm{C}$ by 24 hours.

\section{Optimization to Biomass Production of Lactobacillus fermentum by Submerged Fermentation}

Aiming to increase biomass production the molasses of sugar cane was used as source of carbon and different fonts of nitrogen were tested. The experimental plannings were realized according to Haaland (1989) and Barros et al., (1996). The first planning was a fractional factorial of 5 factors and two levels $\left(2^{5-1}\right)$, being the factors independent sugar cane molasses, yeast extract, meat extract, inoculum tax and fermentation time, all evaluated in two levels (level -1 and level +1 ), with a total of 32 experiments and quadruplicate of the central points, as showed in the table 1 .

After selected the significant variables at the first fractional factorial planning, it was applied a second fractional factorial planning with 4 factors and 2 levels $\left(2^{4-0}\right)$ to evaluate possible changes in the effects of the variables about the biomass production (viable cells).

The variable to carbon source was the sugar cane molasses, to the nitrogen source was the yeast extract, the variables inoculum tax and time were also evaluated, all of them with two levels (level -1 and level +1 ), and the central points were investigated in quadruplicate to identify any experimental anomaly. The tested values to the experiments are reported at table 2 .
The significant variables obtained in the factorial planning results $2^{(4-0)}$ were selected to the last step of optimization using a rotational central composed delineation (CCRD) to biomass production. To the CCRD the following pre-selected variables in the anterior planning were inoculum tax and time. These experiments showed axial points (+1.414 and -1.414) and central points in quadruplicate as reported in table 3 , this delineation was realized aiming to evaluate the increasing of biomass production in an already established mean at anterior planning.

\section{Kinetic of EPS Production in Stirred Tank Bioreactor}

To the kinetic study in biomass production of Lactobacillus fermentum it was realized in bioreactor of 2L (Incelth - LH SGI), in ideal conditions previous established. The mean was composed by sugar cane molasses $7 \%(\mathrm{v} / \mathrm{v})$, yeast extract $2.7 \%(\mathrm{p} / \mathrm{v})$ and $\mathrm{pH}$ of 7.0. The inoculum tax was of $20 \%$ (v/v) with $10^{10} \mathrm{CFU} / \mathrm{mL}$ of Lactobacillus fermentum, the fermentation was conducted for a time of $48 \mathrm{~h}$ and temperature of $37^{\circ} \mathrm{C}$. Samplings were done at each 2 hours until 24 hours of fermentation and after this time they started to be done at each 6 hours until complete 48 hours of fermentation. The $\mathrm{pH}$ was kept steady in 6.0 with automatic addition of sodium hydroxide 3 molar.

Evaluation of Probiotic Activity of the Lactobacillus fermentum cepa in Commercial Laying Hens

To evaluate the probiotic activity of the Lactobacillus fermentum LPB, a field experiment was done, using commercial laying hens. The experiment was conducted in the experimental aviary of the Experimental station center of Canguiri, Setor de Agricultural sciences, Federal University of Paraná, Paraná, Brazil. 
In this experiment 192 hens of the race Hissex lineage White and 192 hens of the race Hissex lineage Brown in laying phase were used.

\section{Management and Animals Diet}

The animals were conditioned in galvanized wire measuring $30 \times 40 \times 45$, being two Hissex race hens of Brown lineage or three from Hissex race of White lineage by coop, where each repetition consisted of four coops.

To the feeding it was used formulated diet and showed in table 4 , and the calculated analysis of the chicken food are reported in table 5, the hens of the Hissex race lineage White received $110 \mathrm{~g} /$ day of food and the ones of the Hissex race lineage Brown $115 \mathrm{~g} /$ day.

It were three treatments, the first one containing the probiotic cepa Lactobacillus fermentum with concentration of $10^{10}$ $\mathrm{CFU} / \mathrm{g}$, the second treatment containing commercial probiotic cepa of Bacillus cereus modified with concentration of $10^{10}$ $\mathrm{CFU} / \mathrm{g}$ and the third one did not presented probiotics in its formulation. The experiment took eleven months.

\section{Studied Variables}

The eggs daily production was evaluated with daily count of eggs for each treatment.

\section{Statistical Analysis}

To the statistical analysis of the biomass production optimization results the software Statsoft Inc., version 5.1, EUA was used. It were also applied the normality tests, the variance analysis (ANOVA) followed by Tukey's post-test, $\mathrm{p}<0.05$ were considered to be statistically significant.

\section{Results and Discussion}

\section{Composition of Culture Medium}

The sugar cane molasses is a rich substrate to fermentable carbohydrates, the determination of the chemical composition was performed to assess the nutritional status.

As shown in table 6, sugar cane molasses has high concentration of total sugars and $19.54 \%$ reducing sugars. For the growth of lactic acid bacteria is required substrate which meets the nutritional and energy needs, and appropriate source of carbon and nitrogen to promote biomass production (Badel et al., 2011). So the sugar cane molasses is low in nitrogen source is required supplementation with a good source of nitrogen.

For all experiments we used the same batch of sugar cane molasses with the same physico-chemical characteristics in order to meet the ICH (1995) and the ANVISA (2011), which it recommends that for obtaining biomolecules by fermentation processes is necessary to maintain the production conditions such as: strain of microorganisms, batch cultivations means of standard and always with the same physicochemical characteristics, because any change in these parameters directly affects the quality and characteristics of the biomolecule produced which prevents any study as well as the reproducibility of the same.

\section{Optimization of Lactobacillus fermentum Biomass Production by Submerged Fermentation}

The sugar cane molasses has potential for use as fermentation substrate, however, a previous study with molasses concentration 
of $10 \%$ and three sources of nitrogen was conducted in order to select the best source of nitrogen for the production of biomass Lactobacillus fermentum.

The best $L$. fermentum biomass production with $2.25 \mathrm{~g} / \mathrm{Lit}$ was obtained in the medium $10 \%$ sugar cane molasses with yeast extract $0.8 \%$, the second best result was the production with the addition of meat extract $0.8 \%$ sugar cane molasses to produce 1.70 $\mathrm{g} / \mathrm{L}$ as seen in figure 1 . According to the statistical analysis ANOVA there was significant difference $(p<0,05)$ biomass produced on substrates and tested. Tukey's post-test showed a significant difference ( $p$ $<0,05)$ in biomass production when compared the results between the different sources and the commercial environment MRS (Man, Rogosa \& Sharp), however comparing the peptone and meat extract there was no significant difference.

\section{Experimental Design}

To improve the production of biomass $L$. fermentum is necessary to have a good source of carbon and nitrogen as well as physico-chemical conditions such as temperature, $\mathrm{pH}$, appropriate stirring, these parameters promote microbial growth (Badel et al., 2011).

Often higher $\mathrm{C}: \mathrm{N}$ ratio has been described as desirable environmental conditions to produce more meaningful (Nampoothiri et al., 2003).

Second Haaland (1989), the majority of biotechnological processes have no theoretical models that may be used for explaining the development process. However there are limitations of time and resources, making the productivity of critical process, therefore, planning and solving problems using tools statistics results in a better resolution of the possibilities to maximize efficiency and productivity.

Thus a study was conducted with statistical planning to list the best conditions to maximize production of biomass for both was used software Statsoft Inc., version 5.1, USA. The first design was a fractional factorial of 5 factors and two levels $\left(2^{5-1}\right)$, the correlation coefficient is often used as a measure of fit and should be near 1.0 for a good statistical model (Plackett and Burman, 1946). In this study, there was obtained $R^{2}=$ 0,86 indicating that $86 \%$ of the experimental biomass production data showed satisfactory adjustment.

Statistical analysis of variance (ANOVA) determines that the following values $\mathrm{p}<0.05$ indicate variables that differ significantly. For this study, the inoculum variable rate ( $p$ $=0.0136)$, yeast extract $(\mathrm{p}=0.0026)$ and time $(\mathrm{p}=0.0008)$ that have a significant effect on biomass production to biomass production $3.52 \mathrm{~g} / \mathrm{L}$.

After choosing the yeast extract as nitrogen source and sugar cane molasses remained the source of carbon, it performed a factorial design $2^{(4-0)}$, in order to better define the variables for the production of biomass. The coefficient of variation was the level of significance of $5 \%$, and this planning showed the coefficient of determination $\mathrm{R}^{2}$ $=0.787$ with $78 \%$ satisfactory adjustment. According to the statistical analysis of ANOVA shows that the variables were not significant for the production of biomass of L. fermentum. The highest production of biomass was $3.95 \mathrm{~g} / \mathrm{L}$ for experiment 1 .

Since no significant variable was fixed concentration of sugar cane molasses $7 \%$ and yeast extract $2.7 \%$ and with maximum production 4,7 $\mathrm{g} / \mathrm{L}$. And held a CCRD, to promote increased production of biomass 
evaluating variables inoculum rate and fermentation time. The CCRD the statistical analysis showed the variables inoculum rate and fermentation time. According to the variance analysis (ANOVA) showed CCRD $\mathrm{R}^{2}=0.798$.

The figure 2 shows that the response surface describes the variation in biomass production when different inoculum rates and time were tested in the fermentation, until the optimum point, when the level (upper or lower) emerge around the center of the surface, suggesting that the increase or decrease of any factor will negatively affect the response variable. This surface is represented by the model of equation 1 .

\section{Kinetic L. fermentum Biomass Production in Stirred Tank Bioreactor}

From the experimental design it was possible to determine the best composition of the medium sugar cane molasses base, and then study was conducted $(\mathrm{n}=3)$ fermentation bioreactor with $48 \mathrm{~h}$ time.
The fermentation bioreactor resulted the increase of Lactobacillus fermentum LPB biomass production with production $5.1 \mathrm{~g} / \mathrm{L}$ after 48 hours fermentation as shown in figure 3, while the biomass obtained in traditional medium was $1.3 \mathrm{~g} / \mathrm{L}$. It can be seen that the fermentation bioreactor provides a productivity gain $400 \%$ when they used alternative medium of growing the base sugarcane molasses and yeast extract.

Biomass production was extremely significant after fermentation bioreactor. The increase in biomass production yield was obtained with optimization, for the production of synthetic medium it was 1,3 $\mathrm{g} / \mathrm{L}$ as shown in the table 7 . At the end of production was optimization. Optimization results in a mathematical model that can predict the behavior of the investigated process, finding the optimal conditions for the production. This has been observed in this work and the best conditions were confirmed in the fermentation bioreactor in an increase in production (Haaland, 1989).

Fig.1 Biomass production of L. fermentum in different nitrogen sources.

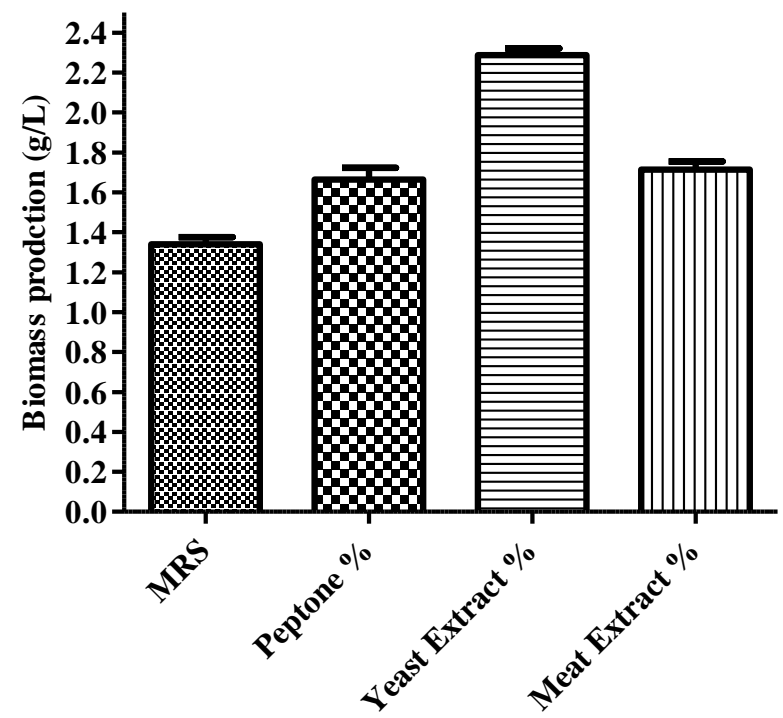


Table.1 Fatorial planning (25-1) to the production of biomass with 5 independant variables, 4 central points (ct) and the valoresdecodificados

\begin{tabular}{|c|c|c|c|c|c|}
\hline Essays & $\begin{array}{c}\text { Cane molasses } \\
\%\end{array}$ & $\begin{array}{c}\text { Yeast } \\
\text { extract \% }\end{array}$ & $\begin{array}{c}\text { Meat } \\
\text { extract \% }\end{array}$ & $\begin{array}{c}\text { Inoculum } \\
\text { tax \% }\end{array}$ & Time hours \\
\hline 1 & 7 & 1.8 & 1.8 & 15 & 40 \\
\hline 2 & 7 & 1.8 & 1.8 & 15 & 24 \\
\hline 3 & 7 & 1.8 & 1.8 & 5 & 40 \\
\hline 4 & 7 & 1.8 & 1.8 & 5 & 24 \\
\hline 5 & 7 & 1.8 & 0.6 & 15 & 40 \\
\hline 6 & 7 & 1.8 & 0.6 & 15 & 24 \\
\hline 7 & 7 & 1.8 & 0.6 & 5 & 40 \\
\hline 8 & 7 & 1.8 & 0.6 & 5 & 24 \\
\hline 9 & 7 & 0.6 & 1.8 & 15 & 40 \\
\hline 10 & 7 & 0.6 & 1.8 & 15 & 24 \\
\hline 11 & 7 & 0.6 & 1.8 & 5 & 40 \\
\hline 12 & 7 & 0.6 & 1.8 & 5 & 24 \\
\hline 13 & 7 & 0.6 & 0.6 & 15 & 40 \\
\hline 14 & 7 & 0.6 & 0.6 & 15 & 24 \\
\hline 15 & 7 & 0.6 & 0.6 & 5 & 40 \\
\hline 16 & 7 & 0.6 & 0.6 & 5 & 24 \\
\hline 17 & 3 & 1.8 & 1.8 & 15 & 40 \\
\hline 18 & 3 & 1.8 & 1.8 & 15 & 24 \\
\hline 19 & 3 & 1.8 & 1.8 & 5 & 40 \\
\hline 20 & 3 & 1.8 & 1.8 & 5 & 24 \\
\hline 21 & 3 & 1.8 & 0.6 & 15 & 40 \\
\hline 22 & 3 & 1.8 & 0.6 & 15 & 24 \\
\hline 23 & 3 & 1.8 & 0.6 & 5 & 40 \\
\hline 24 & 3 & 1.8 & 0.6 & 5 & 24 \\
\hline 25 & 3 & 0.6 & 1.8 & 15 & 40 \\
\hline 26 & 3 & 0.6 & 1.8 & 15 & 24 \\
\hline 27 & 3 & 0.6 & 1.8 & 5 & 40 \\
\hline 28 & 3 & 0.6 & 1.8 & 5 & 24 \\
\hline 29 & 3 & 0.6 & 0.6 & 15 & 40 \\
\hline 30 & 3 & 0.6 & 0.6 & 15 & 24 \\
\hline 31 & 3 & 0.6 & 0.6 & 5 & 40 \\
\hline 32 & 3 & 0.6 & 0.6 & 5 & 24 \\
\hline $33(\mathrm{CP})$ & 5 & 1.2 & 1.2 & 10 & 32 \\
\hline $34(\mathrm{CP})$ & 5 & 1.2 & 1.2 & 10 & 32 \\
\hline $35(\mathrm{CP})$ & 5 & 1.2 & 1.2 & 10 & 32 \\
\hline $36(\mathrm{CP})$ & 5 & 1.2 & 1.2 & 10 & 32 \\
\hline
\end{tabular}


Table.2 Factorial planning (24-0) to the biomass production with 4 independant variables, 4 central points (cp) and decoded values.

\begin{tabular}{lcccc}
\hline Essays & Cane Molasses \% & Yeast Extract \% & Inoculum Tax \% & Time hours \\
\hline 1 & 7 & 2.7 & 20 & 48 \\
2 & 7 & 2.7 & 20 & 32 \\
3 & 7 & 2.7 & 10 & 48 \\
4 & 7 & 2.7 & 10 & 32 \\
5 & 7 & 0.9 & 20 & 48 \\
6 & 7 & 0.9 & 20 & 32 \\
7 & 7 & 0.9 & 10 & 48 \\
8 & 7 & 0.9 & 10 & 32 \\
9 & 3 & 2.7 & 20 & 48 \\
10 & 3 & 2.7 & 20 & 32 \\
11 & 3 & 2.7 & 10 & 48 \\
12 & 3 & 2.7 & 10 & 32 \\
13 & 3 & 0.9 & 20 & 48 \\
14 & 3 & 0.9 & 20 & 32 \\
15 & 3 & 0.9 & 10 & 48 \\
16 & 3 & 0.9 & 10 & 32 \\
$17(\mathrm{CP})$ & 5 & 1.8 & 15 & 40 \\
$18(\mathrm{CP})$ & 5 & 1.8 & 15 & 40 \\
$19(\mathrm{CP})$ & 5 & 1.8 & 15 & 40 \\
$20(\mathrm{CP})$ & 5 & 1.8 & 15 & 40 \\
\hline
\end{tabular}

Table.3 Rotational composed central delineation (CCRD). Decoded values and values of coded tested factors levels

\begin{tabular}{lcc}
\hline Essays & Inoculum tax \% & time hours \\
\hline 1 & 20.00 & 32.00 \\
2 & 20.00 & 48.00 \\
3 & 40.00 & 32.00 \\
4 & 40.00 & 48.00 \\
5 & 14.14 & 40.00 \\
6 & 44.14 & 40.00 \\
7 & 30.00 & 14.14 \\
8 & 30.00 & 44.14 \\
9 (cp) & 30.00 & 40.00 \\
$10(\mathrm{cp})$ & 30.00 & 40.00 \\
$11(\mathrm{cp})$ & 30.00 & 40.00 \\
$12(\mathrm{cp})$ & 30.00 & 40.00 \\
\hline
\end{tabular}


Table.4 Experimental food with $2.52 \%$ of oil

\begin{tabular}{ll}
\hline Ingredients & Quantity $(\mathbf{K g})$ \\
\hline Milledcorn & 53.750 \\
Soybean & 27.090 \\
Wheatbran & 4.380 \\
Soybeanoil & 2.520 \\
Di-calciumphosphate & 1.620 \\
Calcareous & 8.500 \\
Rice rusk & 1.510 \\
Common salt & 0.390 \\
Premix (vitamins and minerals) & 1 \\
Methionine & 0.100 \\
Total & 0.140 \\
\hline
\end{tabular}

1- vit A 2.000.000 UI, vit D3 $525.000 \mathrm{UI}$, vit E $1.750 \mathrm{mg}$, vit K3 $1.500 \mathrm{mg}$, vit B1 $250 \mathrm{mg}$, vit B2 $750 \mathrm{mg}$, vit. B6 $175 \mathrm{mg}$, vit B12 $1.500 \mathrm{mcg}$, niacin $5.000 \mathrm{mg}$, biotin $2,5 \mathrm{mg}$, calciumpantothenate $2.500 \mathrm{mg}$, folicacid $25 \mathrm{mg}$, selenium $50 \mathrm{mg}$, manganese $13.750 \mathrm{mg}$, zinc $12.500 \mathrm{mg}$, copper $1500 \mathrm{mg}$, iron $12.500 \mathrm{mg}$, iodine $250 \mathrm{mg}$, antioxidant $500 \mathrm{mg}$, vehicleq.s.p. $1.000 \mathrm{~g}$.

Table.5 Calculated analysis of the food with $2.52 \%$ of oil.

\begin{tabular}{ll}
\hline Components & Quantity \\
\hline Metabolic energy Kcal/Kg & 2.450 \\
Protein \% & 17.00 \\
Calcium \% & 3.50 \\
Available phosphorus \% & 0.45 \\
Methionine \% & 0.43 \\
Methionine + cysteine \% & 0.71 \\
Lysine \% & 0.95 \\
Sodium \% & 0.18 \\
Linoleic acid \% & 2.65 \\
Crude fibre \% & 3.61 \\
\hline
\end{tabular}

Table.6 Physical and chemical composition of sugar cane molasses

\begin{tabular}{ll}
\hline Components & Quantity (\%) \\
\hline Protein & $0.51 \pm 0.09$ \\
Humidity & $16.44 \pm 0.28$ \\
Ashes & $0.92 \pm 0.03$ \\
Total sugars & $55.20 \pm 0.73$ \\
Reducingsugars & $19.54 \pm 0.62$ \\
\hline
\end{tabular}


Table.7 Increased production of Lactobacillus fermentum biomass during the optimization steps.

\begin{tabular}{lc}
\hline \multicolumn{1}{c}{ Culturemedium } & Biomassproductiong/L \\
\hline Synthetic medium (broth Man, Rogosa e Sharp) & 1,30 \\
${\text { Factorial design } 2^{6-2}}^{5-1}$ & 3,18 \\
Factorial design 2 $^{5-1}$ & 4,03 \\
Factorial design 2 $^{4-0}$ & 4,44 \\
Experimental designCCRD & 4,67 \\
Fermentation in bioreactor & 5,10 \\
\hline
\end{tabular}

Fig.2 Surface response plot showing independent variables inoculum rate and fermentation time.
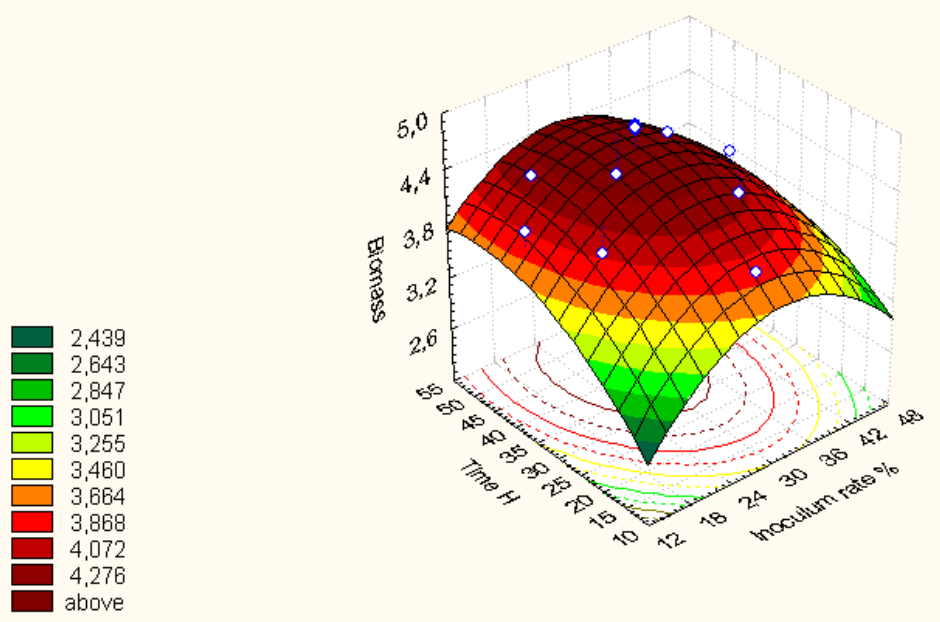

Fig.3 Biomass production kineticsLactobacillus fermentumthrough the sugar cane molasses and yeast extract.
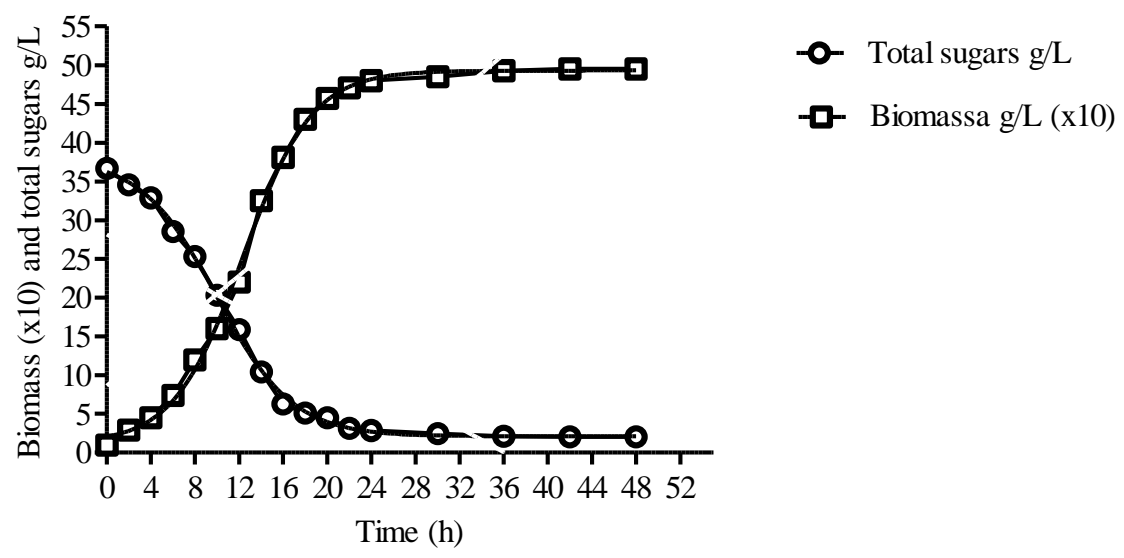
Fig.4 Egg production in the treatments with probiotics and without probiotics.

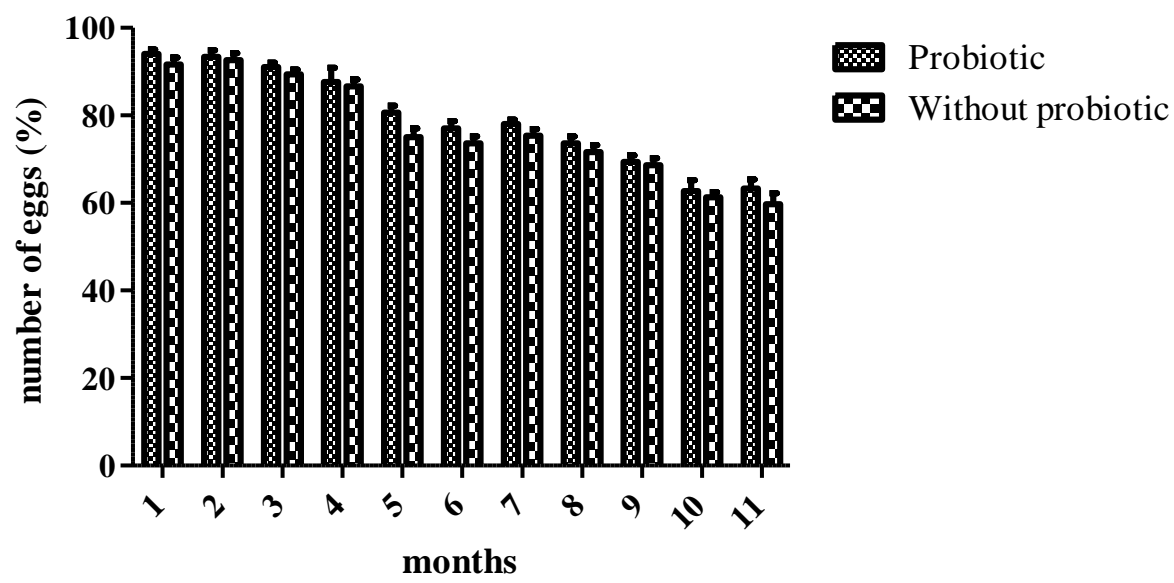

\section{Eggs Production}

Second Lima et al., (2003), the action of the probiotic appears to be mainly related to two factors, the first being the amount of live microorganisms used and second the presence of stress in birds due to the creation of conditions. Therefore, the use of probiotics is indicated in the management of birds not leave residues in products of animal origin, not promote resistance to drugs and mainly favor the animal health conditions (Patterson and Burkholder, 2003; Panda et al., 2008).

According to the statistical analysis ANOVA was observed that there is a significant difference $(\mathrm{p}<0,05)$ as egg production with probiotic and without probiotic. And that the best results were obtained on the fifth and sixth month of production for treatments with probiotic 80.6 average eggs, whereas in the treatments without probiotics production was 75 average eggs. In other months occurred very close egg production between treatments, as shown in figure 4. Also an improvement in health was observed in laying hens who received diet with inclusion of probiotics, which are more resistant infections.
The use of probiotics, prebiotics and synbiotics when used in poultry feed improves health, eggs size, eggs quality and production, and lower feed cost in layins hens (Kurtoglu et al., 2004; Panda et al., 2008). Abdelqader et al., (2013) noted the benefits of including strain of Bacillus subtilis in diet laiyng hens, improving the quality of eggs mainly the eggshells.

In this study it was found that egg production was higher in the treatments with the inclusion of the strain of probiotic Lactobacillus fermentum compared to treatments without probiotics.

\section{References}

Abdelqader, A., Rahman, A., Fataftah, A., Das, G. 2013. Effects of dietary Bacillus subtilis and inulin supplementation on performance, eggshell quality, intestinal morphology and microflora composition of laying hens in the late phase of production. Anim. FeedSci. Tech., 179: 103-111. ANVISA - Agência Nacional de Vigilância 
Sanitária. Guia para Realização do Exercício de Comparabilidade para Registro de Produtos Biológicos. Brasília, p.12, 2011.

Awad, W.A., Ghareeb, K., Abdel-Raheem, S., Bohm, J. 2009. Effects of dietary inclusion of probiotic and symbiotic on growth performance, organ weights, and intestinal histomorphology of broiler chickens. Poult. Sci., 88: 49-55.

Badel, S.,Bernardi, T., Michaud, P. 2011. New perspective for Lactobaclli exopolysaccharides. Biotechnol. $A d v ., 29:$ 54-66.

Choe, D.W., Loh, T.C., Foo, H.L., HairBejo, M., Awis, Q.S. 2012. Egg production, faecal $\mathrm{pH}$ and microbial population, small intestine morphology, and plasma and yolk cholesterol in laying hens give liquid metabolites produced by Lactobacillus plantarum strains. Poult. Sci., 53: 106-115.

Dubois, M., Gilles, K.A., Hamilton, J.K., Smith, P.A. 1956.Colorimetric method for determination of sugars and related substances. Analitycal Chem., 28: 350-356.

Gaggia, F., Mattarelli, P., Biavati, B. 2010. Probiotics and prebiotics in animal feeding for safe food production.Int. J. Food Microbiol., 141: 15-28.

Giampauli, J., Pedroso, A.A., Moraes, V.M.B. 2005. Desempenho e qualidade de ovos de poedeiras após a muda forçada suplementadas com probiótico em diferentes fases de criação. Cienc. Anim. Bras., 6: 179186.

Haaland, P.D. 1989. Experimental design in biotechnology. New York: Marcel Dekker Inc., 1989.

$\mathrm{ICH}$ - International Conference on Harmonisation of technical requirements for registration of pharmaceuticals for human use. Harmonised tripartite guideline Quality of biotechnological products: stability testing of biotechnological/ biological.USA, p. 8, 1995.

Knap, I., Kehlet, A.B., Bennedsen, M., Mathis, G.F.C., Hofacre, L., Lumpkins, B.S., Jensen, M.M., Raun, M., Lay, A. 2011. Bacillus subtillis (DSM 17299) significantly reduces Salmonella in broilers. Poult. Sci., 90: 1690-1694.

Kurtoglu, V., Kurtoglu, F., Seker, E., Coskun, B., Balevi, T., Polat, E.S. 2004. Effect of probiotic supplementation on laying hens diets on yield performance and sérum and egg yolk cholesterol. Food Addit. Contam., 21: 817-823.

Lima, F.V.Z., Pizauro Júnior, J.M.,Macari, M. 2003. Efeito do uso de probiótico sobre o desempenho e atividade de enzimas digestivas de frangos de corte. Rev. Bras. Zootec., 32: 200207.

Lowry, O.H., Rosebrough, N.J., Farr, A.L., Randall, K.L. 1951. Protein measurement with the Folin phenol reagent.J. Biol. Chem., 183: 265.

Miller, G. L. 1959. Use of dinitrosalicylic acid reagent for determination of reducing sugar. Analitycal Chem., 31: 426-428.

Mohiti Asli, M., Hosseini, S.A., Lotfollahian, H. 2007. Effect of probiotics,yeast, vitamin $\mathrm{E}$ and vitamin $\mathrm{C}$ supplements on performance and immune response of laying hen high environment temperature. J. Poult. Sci. 6: 895900.

Nampoothiri, K.M., Singhania, R.R., Sabarinath, C., Pandey, A. 2003. Fermentative production of gellan using Sphingomonas paucimobilis. Process Biochem., 38: 1513-1519. 
Panda, A.K., Rama Rao, S.S., Raju, M.V.L.N., Sharma, S.S. 2008. Effect of probiotic.

Patterson, J.A., Burkholder, K.M. 2003. Application of prebiotics and probiotics in poultry production. Poult. Sci., 82: 627-631.

Plackett, R.L., Burman, J.P. 1946. He design of multifactorial experiments.
Biometrika, 33: 305-325.

Scholz-Ahrens, K.E., Ade, P., Marten, B., Weber, P., Timm, W., Asil, Y., Gluer, C.C., Schrezenmeir, J. 2007. Prebiotics, probiotics and synbiotics affect mineral absorption, bone mineral content and bone structure. J. Nutr., 137: 838-846.

\section{How to cite this article:}

Maria Rosa Machado Prado, Sebastião Gonçalves Franco and Carlos Ricardo Soccol. 2016. Development of a Fermentation Medium for Production of Probiotics and their Use in Feed for Laying Hens. Int.J.Curr.Microbiol.App.Sci. 5(6): 357-369. doi: http://dx.doi.org/10.20546/ijcmas.2016.506.041 